\title{
Nucleotide Composition of Nucleic Acids of Fungi
}

\author{
I. Ribonucleic Acids \\ ROGER STORCK \\ Department of Microbiology, The University of Texas, Austin, Texas
}

Received for publication 25 June 1965

\begin{abstract}
Storck, Roger (The University of Texas, Austin). Nucleotide composition of nucleic acids from fungi. I. Ribonucleic acids. J. Bacteriol. $90: 1260-1264$. 1965.-The nucleotide composition of the ribonucleic acids (RNA) present in extracts of 26 species of fungi was determined. The results were analyzed, together with those in the literature. It was found that the content in moles per cent of guanine plus cytosine (GC content) varied from 44.1 to 60.5 in a distribution composed of 8 species of zygomycetes, 10 of ascomycetes, 11 of deuteromycetes, and 8 of basidiomycetes. The GC-content range and average were, respectively, 44.1 to 49.3 and 46.4 for the zygomycetes, 47.4 to 54.4 and 50.2 for the ascomycetes, 48.2 to 54.5 and 51.6 for the deuteromycetes, and 50.4 to 60.5 and 52.4 for the basidiomycetes. The GC content averaged 45.6 and ranged from 44.1 to 46.3 for four Mucor species. In addition, GC contents significantly lower than 50 were also encountered in some species of Hemiascomycetidae, suggesting that AT type RNA is not uncommon in fungi. It was proposed that the base composition of fungal RNA might have a taxonomic and phylogenetic significance.
\end{abstract}

Information on the base composition of fungal ribonucleic acid (RNA) stems primarily from the work of Uryson and Belozersky (1960) and of Vanyushin, Belozersky, and Bogdanova (1960). These authors analyzed a total of 12 species distributed among myxomycetes, phycomycetes, ascomycetes, and deuteromycetes, and concluded that to a certain extent the nucleotide composition of total RNA (ribosomal RNA plus transfer RNA plus informational RNA) was speciesspecific. These authors found that the compositional diversity in RNA was smaller than in deoxyribonucleic acid (DNA) and that the guanine plus cytosine content (GC) of RNA, when expressed in moles per cent, was distributed between 50 and $55 \%$. One species belonging to the genus Absidia, however, had RNA characterized by $44.8 \%$ GC. This value was the lowest ever reported and, together with $47.2 \%$ GC found by Elson and Chargaff (1955) for Saccharomyces cerevisiae, suggested that the base composition of total RNA from some fungi might be unique.

In the present work, 23 additional species belonging to four classes of eumycotina have been analyzed. The results clearly show that RNA preparations with GC content of less than $50 \%$ are common in fungi. In addition, our values, together with those found in the literature, suggest that the base composition of RNA might have a limited but significant systematic and phylogenetic value for this important group of microorganisms.

\section{Materials and Methods}

Organisms. Organisms were selected in a manner which provided about equal representation from each class, and included yeast as well as filamentous forms. In each class, from two to four species belonging to the same genus were analyzed to determine the degree of similarity of their RNA composition.

Growth and harvest. All organisms were grown at $25 \mathrm{C}$ in submerged cultures, under forced aeration, and in a medium eliciting a maximal rate of growth. In most cases, the inoculum consisted of a mycelial starter and, in some, of a homogenized spore suspension (Storck, 1963). The cultures in the growth phase were harvested by centrifugation or filtration. Pellets and mycelial mats were washed with $0.01 \mathrm{M}$ tris(hydroxymethyl)amino-

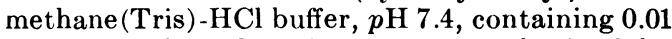
$\mu \mathrm{mole} / \mathrm{ml}$ of $\mathrm{MgCl}_{2}$. Extracts were obtained by grinding with washed 50-mesh sand in chilled mortars, and were cleared of large debris by centrifugation at $15,000 \times g$ for $15 \mathrm{~min}$ at $3 \mathrm{C}$. Although the pellets contained RNA, they were discarded because it was found with Neurospora crassa and Aspergillus niger that deoxycholate extracts containing all the RNA present in these pellets had the same base composition as the RNA in the supernatant fluid. A similar result was obtained with Mucor rouxii; the totality of the RNA was recovered after the treatment with ribonuclease of intact cells which had been precipitated with cold 
trichloroacetic acid. Furthermore, as will be shown in the Results, our base ratio values were in agreement with those of others who analyzed the RNA after direct hydrolysis of the cells. It was therefore concluded that the supernatant fluids analyzed in the present work represent valid samples of the total RNA.

Determination of nucleotide composition. The procedures used for alkaline hydrolysis of RNA and chromatographic separation of nucleotides have been previously described in detail (Henney and Storck, 1963a). Dowex 1 X 8 (200 to 400 mesh) columns (height, 2 to $5 \mathrm{~cm}$; diameter, $1.2 \mathrm{~cm}$ ) in the formate form were used for amounts of RNA varying between 2.0 and $5.0 \mathrm{mg}$. The stepwise elution of the nucleotide was recorded automatically with a Gilford multiple sample absorbance recorder attached to a Beckman DU spectrophotometer. Three hydrolysates were analyzed simulta- neously. Flow cells of 1 -cm light path and a volume of $0.1 \mathrm{~cm}^{3}$ were used. To prevent the formation of air bubbles which interfered with optical density measurements, ice-cold water was circulated through the jacket surrounding the cell chamber. The areas under the curves for each nucleotide in the elution diagram were measured with a planimeter. The volume of eluent and the time required for the elution of each nucleotide were determined to obtain, in each case, an average value for the flow rate. The amount of each nucleotide was found by multiplying the area under the curve, by the reciprocal of the molar extinction coefficients (Beaven, Holiday, and Johnson, 1955), and by the flow rate. The amount of each nucleotide was obtained independently from a direct analysis of the collected eluates. The values found with the automatic procedure for the simultaneous analysis of three hydrolysates were in close agreement with

TABLE 1. Nucleotide composition of RNA from fung $i^{*}$

\begin{tabular}{|c|c|c|c|c|c|c|}
\hline \multirow{2}{*}{ Organism } & \multirow{2}{*}{ No. ${ }^{+}$} & \multicolumn{5}{|c|}{ Moles per 100 moles of identified nucleotides } \\
\hline & & $\mathrm{C}$ & A & $\mathrm{U}$ & G & $\mathrm{G}+\mathrm{C}$ \\
\hline \multicolumn{7}{|l|}{ Zygomycetes } \\
\hline Absidia glauca. & 3 & $19.2 \pm 0.1$ & $26.1 \pm 1.1$ & $26.3 \pm 0.4$ & $28.4 \pm 1.6$ & 47.6 \\
\hline Mucor racemosus (1608) & 6 & $19.2 \pm 0.2$ & $27.9 \pm 0.1$ & $27.5 \pm 0.3$ & $25.4 \pm 0.2$ & 44.6 \\
\hline$M$. rouxianus (4855). & 6 & $20.4 \pm 0.5$ & $27.3 \pm 0.6$ & $26.4 \pm 0.7$ & $25.9 \pm 0.5$ & 46.3 \\
\hline M. rouxianus (8097). & 6 & $19.5 \pm 0.9$ & $28.3 \pm 0.6$ & $27.6 \pm 0.8$ & $24.6 \pm 1.5$ & 44.1 \\
\hline M. rouxii (1894). & 8 & $19.6 \pm 0.2$ & $27.1 \pm 0.2$ & $26.6 \pm 0.2$ & $26.7 \pm 0.3$ & 46.3 \\
\hline M. subtilissimus (1743) & 8 & $19.6 \pm 0.7$ & $27.7 \pm 0.5$ & $26.0 \pm 0.5$ & $26.7 \pm 0.4$ & 46.3 \\
\hline M. subtilissimus (1909) & 6 & $19.8 \pm 0.3$ & $26.9 \pm 0.2$ & $27.3 \pm 0.3$ & $26.0 \pm 0.2$ & 45.8 \\
\hline Phycomyces blakesleeanus. & 6 & $20.8 \pm 1.5$ & $27.8 \pm 2.4$ & $23.6 \pm 1.7$ & $27.8 \pm 1.8$ & 48.6 \\
\hline Zygorhynchus moeller & 2 & $20.0 \pm 0.2$ & $27.4 \pm 0.0$ & $26.9 \pm 0.1$ & $25.7 \pm 0.1$ & 45.7 \\
\hline \multicolumn{7}{|l|}{ Deuteromycetes } \\
\hline Penicillium chrysoge & 3 & $21.5 \pm 0.3$ & $23.5 \pm 0.6$ & $24.5 \pm 1.0$ & $30.4 \pm 0.3$ & 51.9 \\
\hline P. notatum & 3 & $22.8 \pm 0.3$ & $23.5 \pm 0.3$ & $23.8 \pm 0.2$ & $29.9 \pm 0.1$ & 52.7 \\
\hline Candida pulcherrima. & 3 & $23.1 \pm 1.2$ & $26.0 \pm 0.4$ & $22.8 \pm 0.9$ & $28.1 \pm 0.9$ & 51.2 \\
\hline Cryptococcus albidus. & 3 & $19.9 \pm 0.6$ & $22.1 \pm 0.8$ & $25.5 \pm 1.0$ & $32.4 \pm 1.4$ & 52.3 \\
\hline C. laurentii. & 3 & $21.6 \pm 1.3$ & $25.6 \pm 0.4$ & $23.3 \pm 0.8$ & $29.5 \pm 0.6$ & 51.1 \\
\hline Rhodotorula mucilaginosa & 3 & $24.8 \pm 1.6$ & $30.9 \pm 0.3$ & $20.8 \pm 0.5$ & $23.4 \pm 1.6$ & 48.2 \\
\hline Torulopsis stellata & 3 & $22.7 \pm 0.6$ & $27.5 \pm 0.8$ & $21.8 \pm 1.4$ & $27.6 \pm 1.9$ & 50.4 \\
\hline \multicolumn{7}{|l|}{ Ascomycetes } \\
\hline Endomyces $r$ & 3 & $19.6 \pm 0.1$ & $26.8 \pm 0.5$ & $25.4 \pm 0.7$ & $28.2 \pm 0.4$ & 47.8 \\
\hline Debaryomyces kloeckeri. & 3 & $20.2 \pm 0.7$ & $27.2 \pm 0.7$ & $25.4 \pm 0.4$ & $27.2 \pm 0.3$ & 47.4 \\
\hline Lipomyces starkeyi. & 3 & $23.2 \pm 1.3$ & $23.0 \pm 1.6$ & $22.6 \pm 0.5$ & $31.3 \pm 1.4$ & 54.4 \\
\hline Pichia membranaefaciens & 6 & $24.0 \pm 1.9$ & $24.8 \pm 1.8$ & $22.6 \pm 1.2$ & $28.6 \pm 1.0$ & 52.6 \\
\hline Saccharomyces cerevisiae & 3 & $20.1 \pm 0.6$ & $26.6 \pm 0.4$ & $26.5 \pm 0.6$ & $26.7 \pm 1.0$ & 46.8 \\
\hline S. fragilis & 2 & $21.9 \pm 0.1$ & $27.1 \pm 0.8$ & $25.4 \pm 0.6$ & $25.6 \pm 0.1$ & 47.4 \\
\hline Schizosaccharomyces octosporus & 3 & $23.1 \pm 0.6$ & $24.0 \pm 0.2$ & $24.4 \pm 0.6$ & $28.4 \pm 0.5$ & 51.5 \\
\hline \multicolumn{7}{|l|}{ Basidiomycetes } \\
\hline & 3 & $23.0 \pm 0.4$ & $25.0 \pm 0.4$ & $22.9 \pm 0.4$ & $29.1 \pm 0.6$ & 52.1 \\
\hline S. salmonicolor. & 6 & $22.8 \pm 1.1$ & $26.8 \pm 2.1$ & $21.6 \pm 1.0$ & $28.8 \pm 1.9$ & 51.7 \\
\hline Schizophyllum commune & 4 & $23.4 \pm 1.0$ & $25.4 \pm 1.0$ & $22.5 \pm 0.5$ & $28.6 \pm 1.1$ & 52.0 \\
\hline
\end{tabular}

* $\mathrm{C}$, cytidylic acid; A, adenylic acid; U, uridylic acid; G, guanylic acid. The numbers in parentheses after the Mucor species refer to strains from the Northern Regional Research Laboratory. Peoria, Ill.

$\uparrow$ Number of analyses. 
TABLE 2. Nucleotide composition of RNA from fungi as reported in the literature*

\begin{tabular}{|c|c|c|c|c|c|c|}
\hline \multirow{2}{*}{ Organism } & \multicolumn{5}{|c|}{ Moles per 100 moles of identified nucleotides } & \multirow{2}{*}{ Reference } \\
\hline & $\mathrm{C}$ & A & $\mathrm{U}$ & G & GC & \\
\hline \multicolumn{7}{|l|}{ Zygomycetes } \\
\hline $\begin{array}{l}\text { Lichtheimia } \ddagger \text { species...... } \\
\text { Phycomyces blakesleeanus }\end{array}$ & 19.5 & 28.8 & 26.4 & 25.3 & 44.8 & 1 \\
\hline$(-) \ldots \ldots \ldots \ldots \ldots$ & 21.1 & 28.2 & 21.0 & 29.7 & 50.8 & 2 \\
\hline$(+) \ldots \ldots \ldots$ & 21.2 & 27.4 & 21.5 & 29.9 & 51.1 & 2 \\
\hline \multicolumn{7}{|l|}{ Deuteromycetes } \\
\hline Aspergillus niger & 23.9 & 24.2 & 21.9 & 30.0 & 53.9 & 3 \\
\hline & 25.0 & 25.0 & 19.9 & 30.1 & 55.1 & 2 \\
\hline Botrytis cinerea.. & 22.7 & 28.0 & 24.0 & 27.3 & 50.0 & 1 \\
\hline Penicillium stolonifer. . & 23.6 & 24.9 & 24.7 & 27.0 & 50.6 & 4 \\
\hline Trichothecium roseum. . & 23.7 & 25.8 & 20.8 & 29.7 & 51.4 & 1 \\
\hline \multicolumn{7}{|l|}{ Ascomycetes } \\
\hline Neurospora crassa. & 23.7 & 24.7 & 24.2 & 27.4 & 51.0 & 5 \\
\hline & 25.9 & 23.7 & 24.2 & 26.2 & 52.1 & 6 \\
\hline Helvella esculenta. & 22.3 & 25.7 & 23.6 & 28.4 & 50.7 & 1 \\
\hline Sclerotinia libertinia. & 21.9 & 28.0 & 21.8 & 28.3 & 50.2 & 2 \\
\hline \multicolumn{7}{|l|}{ Basidiomycetes } \\
\hline Polyporus versicolor. & 25.9 & 20.0 & 19.4 & 34.6 & 60.5 & 7 \\
\hline Amanita muscaria. . & 21.3 & 27.7 & 21.6 & 29.4 & 50.7 & 1 \\
\hline A. strobiliformis... & 22.2 & 24.1 & 24.9 & 28.8 & 51.0 & 7 \\
\hline Agaricus bisporus..... & 21.6 & 24.2 & 22.4 & 28.8 & 50.4 & 2 \\
\hline Lycoperdon species.... & 22.7 & 27.0 & 22.3 & 28.0 & 50.7 & 1 \\
\hline
\end{tabular}

* C, cytidylic acid; A, adenylic acid; U, uridylic acid; $\mathrm{G}$, guanylic acid.

$\dagger 1$, Vaniushin et al. (1960); 2, Uryson and Belozersky (1960); 3, Moyer and Storck (1964); 4, Kleinschmidt and Manthey (1958); 5, Henney and Storck (1963); 6, Minagawa, Wagner, and Strauss (1959); 7, Venner (1963).

$\ddagger$ Absidia.

those found in the literature and those obtained earlier in our laboratory (Henney and Storck, $1963 a, b ;$ Moyer and Storck, 1964).

\section{RESUlts}

The results of our determinations are shown in Table 1. For each nucleotide the value indicated represents the mean for two to eight analyses. The average deviation from this mean rarely exceeded $\pm 2 \%$ and often was less than $\pm 1 \%$. In this respect, our results carry the same weight as those reported in the literature. The mean GC content is found in the last column. In most instances, the average deviation from this mean equals $\pm 2 \%$ or less.

The nucleotide composition of RNA from fungi other than those investigated in the present work is presented in Table 2. For Aspergillus niger and Neurospora crassa, two sets of values have been included to permit a comparison of the results obtained in two laboratories. As seen for both organisms, the GC contents do not differ by more than $1.5 \%$. The average GC for the $(+)$ and (-) strains of Phycomyces blakesleeanus deviates from our corresponding value (Table 1) by $2.3 \%$. Similarly, for Saccharomyces cerevisiae, our value of 46.8 is in agreement with the 47.2 reported by Elson and Chargaff (1955), with Crosbie, Smellie, and Davidson (1953), and with other values found in the literature: 47.7 (Midgley, 1962; Osawa, 1960), 48.4 (Fukuhara and Shortman, 1962), 51.2 (Kitazume and Ycas, 1963). This high value of 51.2 apparently results from the fact that potassium ions were not removed from the hydrolysates, a procedure which, according to these authors, causes a loss of guanylic acid by coprecipitation. If we exclude this last value from our comparison, the GC content of RNA from $S$. cerevisiae ranges from 46.8 to 48.4 .

Since our results agree with those obtained in other laboratories, the GC-content values shown in Tables 1 and 2 were grouped. In Table 3, the average and range in GC content found for each taxonomic group are presented. The average value was used in the case of organisms for which several independent analyses were available. With the Mucor species, six strains belonging to four species were analyzed (Table 1). In total, 37 different species of fungi have been used for the calculations shown in Table 3. 
TABLE 3. Distribution of GC content of $R N A$ among fungi

\begin{tabular}{|c|c|c|c|}
\hline Taxonomic group & No.* & Range $†$ & Avg $\dagger$ \\
\hline All classes. & 37 & $44.1-60.5(16)$ & 50.2 \\
\hline Zygomycetes. & 8 & $44.1-49.3(5)$ & 46.4 \\
\hline Ascomycetes. & 10 & $47.4-54.4 \quad(7)$ & 50.2 \\
\hline Basidiomycetes & 8 & $50.4-60.5 \quad(10)$ & 52.4 \\
\hline Deuteromycetes. & 11 & $48.2-54.5(6)$ & 51.6 \\
\hline Mucor . . . . . . & 4 & $44.1-46.3(2)$ & 45.6 \\
\hline Hemiascomycetidae. & 7 & $47.4-54.4 \quad(7)$ & 49.9 \\
\hline Euascomycetidae... & 3 & $50.2-51.6(1)$ & 50.8 \\
\hline
\end{tabular}

* Number of species analyzed.

$\dagger$ The range and average values are expressed in moles per cent GC.

\section{Discussion}

The GC content of fungal RNA ranges from 44 to $60 \%$. The higher value was reported by Venner (1963) for one species of Polyporus. This unique composition reflects a content of $34.6 \%$ in guanylic acid. Further investigation of this genus and related genera is required to establish whether the compositional diversity of RNA from fungi is indeed greater than in the other groups of organisms. If Polyporus is omitted, the GC content varies from 44 to $55 \%$. In absolute value, this variation is equal to the range for bacterial RNA (Belozersky and Spirin, 1960).

Vanyushin et al. (1960) found that the RNA from one Absidia (Lichtheimia) species contained $44.8 \%$ GC. The present work confirms this finding and further demonstrates that such values are not uncommon in fungi. Indeed, average GC contents of $46.9 \pm 1.3$ and $47.2 \pm$ 0.5 were found, respectively, for the mucorales and for a group composed of one species of Endomyces, one of Debaryomyces, and two of Saccharomyces. A survey of the literature reveals that AT type RNA preparations are rarely encountered. No GC contents significantly lower than $50 \%$ were found for bacteria (Belozersky and Spirin, 1960) and for plants (Trim, Baker, and Leah, 1964) in studies of the same amplitude as the present one.

A small number of fungi have been analyzed. The significance of GC ranges and averages is therefore weak. If this is kept in mind, it is perhaps permissible to note that the GC distribution for the mucorales and the ascomycetes overlaps significantly. This overlapping results from the low GC content exhibited by the RNA from some Hemiascomycetidae. It is tempting to speculate on a possible link between the zygomycetes and the ascomycetes. This speculation is supported somewhat by the fact that the GC distribution of the mucorales and the basidiomycetes does not overlap.

\section{ACKNowledgments}

This investigation was supported by Public Health Service research grant AI-04431 from the National Institute of Allergy and Infectious Diseases.

We thank C. J. Alexopoulos, C. W. Hesseltine, and $\mathrm{H}$. Phaff for kindly supplying some of the organisms. The technical assistance of Mrs. R. Morrill and C. Hartt is gratefully acknowledged.

\section{Literature Cited}

Beaven, G. H., E. R. Holiday, and E. A. Johnson. 1955. Optical properties of nucleic acids and their components, p. 493-553. In E. Chargaff and J. N. Davidson [ed.], The nucleic acids, vol. 1 . Academic Press, Inc., New York.

Belozersky, A. N., and A. S. Spirin. 1960. Chemistry of the nucleic acids of microorganisms, p. 147-185. In E. Chargaff and J. N. Davidson [ed.], The nucleic acids, vol. 1. Academic Press, Inc., New York.

Crosbie, G. W., R. M. S. Smellie, and J. N. DAvidson. 1953. The composition of the cytoplasmic and nuclear ribonucleic acids of the liver cell. Biochem. J. 54:287-292.

Elson, D., and E. Chargaff. 1955. Evidence of common regularities in the composition of pentose nucleic acids. Biochim. Biophys. Acta $17: 367-376$.

Fukuhara, H., and K. Shortman. 1962. Le metabolisme de l'acide ribonucleique pendant l'adaptation respiratoire de la levure. Compt. Rend. 255:1529-1531.

Henney, H., And R. Storck. 1963a. Nucleotide composition of ribonucleic acid from Neurospora crassa. J. Bacteriol. 85:822-826.

Henney, H., and R. Storck. 1963b. Ribosomes and ribonucleic acids in three morphological states of Neurospora. Science 142:1675-1677.

Kitazume, Y., and M. YCas. 1963. The calculated composition of newly synthesized yeast ribonucleic acid. Biochim. Biophys. Acta 76:391-400.

Kleinschmidt, W. J., And J. A. Manthey. 1958. Quantitative determination of nucleic acids in whole tissue by paper chromotography. Arch. Biochem. Biophys. 73:52-64.

Midgley, J. E. M. 1962. The nucleotide base composition of ribonucleic acid from several microbial species. Biochim. Biophys. Acta 61:513-525.

Minagawa, T., B. Wagner, and B. Strauss. 1959. The nucleic acid content of Neurospora crassa. Arch. Biochem. Biophys. 80:442-445.

Moyer, R. C., AND R. Storck. 1964. Properties of ribosomes and RNA from Aspergillus niger. Arch. Biochem. Biophys. 104:193-201.

OsawA, S. 1960. The nucleotide composition of ribonucleic acids from subcellular components of yeast. Escherichia coli and rat liver, with special reference to the occurrence to the pseudouridylic acid in soluble ribonucleic acid. Biochim. Biophys. Acta $42: 244-254$. 
Storck, R. 1963. Characterization of ribosomes from Neurospora crassa. Biophys. J. 3:1-9.

Trim, A. R., J. E. Baker, AND A. B. Leah. 1964. The isolation and composition of ribonucleic acids from leaves. Biochem. J. 93:14-26.

Uryson, S. O., AND A. N. Belozersky. 1960. Nucleotide composition of deoxyribonucleic and ribonucleic acids of certain fungi. Dokl. Akad. Nauk SSSR 133:708-710.
Vanyushin, B. F., A. N. Belozersky, and S. L. Bogdanova. 1960. A comparative study of the nucleotide composition of ribonucleic acid and deoxyribonucleic acids in some fungi and myxomycetes. Dokl. Akad. Nauk SSSR 134:12221225.

VenNeR, H. 1963. Isolierung und Untersuchung von Nucleuisauren aus Basidiomyceten. Z. Physiol. Chem. 333:5-19. 